\title{
High frequency of primary hereditary ichthyoses in the North-East region of Cairo, Egypt
}

\author{
Nermine El-Sayed ${ }^{1}$, Neveen S. Seifeldin² ${ }^{2}$ Christine K.T. Gobrial ${ }^{2}$ \\ ${ }^{1}$ Medical Genetics Center, Ain Shams University, Cairo, Egypt \\ 2Dermatology, Venereology and Andrology Department, Ain Shams University, Cairo, Egypt \\ Adv Dermatol Allergol 2018; XXXV (2): 161-166 \\ DOI: https://doi.org/10.5114/ada.2018.75238
}

\begin{abstract}
Introduction: Inherited ichthyoses are caused by mutations in various genes important for keratinocyte differentiation and epidermal barrier function. Although ichthyoses are rare disorders, they require costly long-term medical management, and thus there is a need for efficient preventive and therapeutic strategies.

Aim: We performed a retrospective study to determine the frequency, types, clinical presentation and associated genomic errors of primary hereditary ichthyoses in Egyptian patients and their relatives consulting the Genetics Clinic, Pediatric Hospital, Ain Shams University.

Material and methods: The outpatient log books of patients between January 2000 and December 2014 were reviewed, and diagnosis of new patients was confirmed through examination by a dermatologist. All epidemiologic, demographic, and clinical data were extracted and recorded in especially designed data collection forms.

Results: The occurrence rate of primary hereditary ichthyoses in our study was $25.7 \%$ of genodermatosis patients attending the genetics clinics and 1 per 2359 patients attending the Pediatric Hospital. The commonest type of ichthyosis in our study was Lamellar ichthyosis (38\%), followed by congenital ichthyosiform erythroderma (26.8\%). Consanguineous marriage was reported among the parents of $79 \%$ of patients and positive family history was reported in $72 \%$ of patients.

Conclusions: To the best of our knowledge, this preliminary study is the first report on the clinico-epidemiological features of primary hereditary ichthyoses in Egypt. The high rate of prenatal consanguinity among parents of our patients may account for the high frequency of these genodermatoses in Egypt. This highlights the importance of genetic counselling and prenatal diagnosis in Egypt.
\end{abstract}

Key words: Egypt, frequency, hereditary, ichthyosis, primary.

\section{Introduction}

Inherited ichthyoses, defined as the generalized form of Mendelian disorders of cornification, are characterized by visible scaling and/or hyperkeratosis of most or all of the skin. This etiologically and phenotypically heterogeneous group of conditions is caused by mutations in various different genes important for keratinocyte differentiation and epidermal barrier function [1]. More than 25 genes have been identified that encode a wide spectrum of epidermal proteins, including enzymes of lipid metabolism and of peptide cross-linking, proteases and their inhibitors, epidermal structural proteins, and proteins involved in cellular communication, signaling and gene transcription. Abnormalities in any of these components result in a rather stereotypic epidermal response with epidermal hyperplasia and the formation of excess stratum corneum (SC) accompanied by abnormal delayed and/or disordered desquamation, with visible accumulation of scales on the skin surface $[2,3]$.

Over the years much progress has been made in defining the molecular causes of ichthyosis, however there is no internationally accepted classification and terminology. It was agreed that classification remains clinically based and distinguishes between syndromic and non-syndromic ichthyosis forms [1, 4, 5]. Distinguishing between specific subtypes requires careful assessment of clinical features. Associated cutaneous and extracutaneous features, as well as disease onset and clinical course, provide important diagnostic clues. In all forms of Mendelian Disorders of Cornification (MeDOC), the clinical presentation may be variable in both severity and in the expression of associated features, and at times

Address for correspondence: Neveen S. Seifeldin MD, Department of Dermatology, Venereology and Andrology, Faculty of Medicine, Ain Shams University, 2 Tomanbayst. Heliopolis, Cairo, Egypt, phone: 202 22585577, fax: 202 22585577, e-mail: drnevins@hotmail.com Received: 16.11.2016, accepted: 25.01.2017. 
additional laboratory testing including microscopy and genetic analyses is required $[1,6-8]$.

There is limited clinico-epidemiologic information on primary hereditary ichthyoses (PHI) in Egypt. Given this background, the objective of this study was to illustrate phenotypic variability and frequency of various types of PHI in an ethnically fairly homogeneous country like Egypt. Herein, we conduct a retrospective study to determine the frequency, types, clinical presentation and associated genomic errors in $\mathrm{PHI}$ patients and their relatives in the Genetics Clinic, Pediatric Hospital, Ain Shams University. This hospital is located in the northeast section of Cairo, and is the second largest hospital in Egypt. It has a high standard of health care, so nearly all patients in this area attend this hospital for consultation. Also patients come nearly from all regions of Egypt to obtain good health care. So, the frequency and characteristics of ichthyosis in this hospital will represent that in the general population to a great extent.

\section{Material and methods}

The present study comprised 284 index patients with $\mathrm{PHI}$ out of 1106 index patients with genodermatoses who were registered at the Genetics outpatient clinic, pediatric hospital, Ain Shams University, and 670,000 patients attending the whole pediatric hospital between January 2000 and December 2014.

The outpatient department log books of these patients were reviewed by a geneticist and a dermatologist, and diagnosis of new patients was confirmed through examination by a dermatologist. The medical records of these patients were reviewed and all the epidemiological, demographic, and clinical data were extracted and recorded in especially designed data collection forms.

Diagnosis depended on typical findings at clinical examination, detailed patient and family history, age of onset, sex, scales distribution, presence or absence of erythema, atopic dermatitis, ectropion, mental retardation, convulsions, speech defect and other neurological manifestations. Index pedigree design including parental relationship, and laboratory work up when needed for some patients were also done or reviewed through medical records.

Patients with extra cutaneous findings were also examined by other specialists to assess the possibility of syndromic ichthyosis. Patients prone to infection were examined for the presence of lipid droplets in leucocytes indicating Chanarin-Dorfman syndrome.

\section{Statistical analysis}

The collected data were subsequently entered into a computer database and analyzed statistically using the SPSS program (SPSS Inc. Chicago, IL, USA). This study was approved by the local ethics committee, and all new patients or parents gave informed consent before enrollment in the study.

\section{Results}

Epidemiological features and clinical findings of 284 patients with $\mathrm{PHI}$ are summarized in Table 1.

\section{Occurrence rate}

Out of 1106 new genodermatosis patients attending the Genetics outpatient clinics during the period of the study, 284 patients had the diagnosis of $\mathrm{PHI}$ confirmed clinically and after full investigations. The occurrence rate was $25.7 \%$ of genodermatoses, and 1 per 2359 patients attending the Pediatric hospital, Ain shams University, Cairo, Egypt.

\section{Epidemiological profile}

Of the 284 patients with ichthyosis 138 (48.6\%) were males and 146 (51.4\%) were females, giving a male to female ratio of $0.9: 1$. Consanguineous marriage was reported among the parents of 224 patients out of 284 (79\%), being most noticeable in lamellar ichthyosis (LI) parents (92 out of 284, 32.4\%). Family history of a similarly affected sib or other relative was reported among 204 out of 284 patients (71.6\%).

\section{Age of onset}

In ichthyosis vulgaris (IV) group, all patients had their presentation after the third month of life. In the X-linked ichthyosis $(\mathrm{XLI})$ group, most of the patients presented at birth with collodion membranes (70\%). In the $\mathrm{LI}$ and congenital ichthyosiform erythroderma (CIE) group, all patients presented at birth with a collodion membrane. Most of our Sjogren-Larsson syndrome (SLS) group (75\%) presented after the first month of life with diffuse erythema and scaling.

\section{Clinical phenotypes and skin findings}

The commonest type of ichthyosis in our study was LI 108/284 (38\%), followed by CIE 76/284 (26.8\%), IV; $38 / 284$ (13.4\%) and XLI; 30/284 (10.6\%). Sjogren-Larsson syndrome was detected in 32/284; $11.3 \%$ of our patients.

Of the 284 patients with PHI in our study, 196 (69\%) were born with a collodion membrane. These comprised all babies with $\mathrm{LI}$ and $\mathrm{CIE}$, and 12 babies with XLI (4.2\%) who were born with exaggerated skin desquamation and peeling at birth. Thirty two babies out of 284 (11.3\%) with SLS were born with diffuse erythema and scaling. In $\mathrm{LI}$ and $\mathrm{CIE}$, the scales were mostly generalized and ranged from fine and white (in CIE) to thick, dark and plate like (in LI). While in patients with IV, the scales were small, greyish-white and semi-adherent. In XLI, the scales were large, dark, mainly on the trunk and extensors. The flexures were spared both in IV and XLI patients. In SLS 
patients, the scales were fine with generalized erythema. Severe scaling of the scalp (dandruff) was found in 72 patients of the 284 (25.3\%): 40 with CIE (14\%), 15 with IV (5.3\%), 10 with LI (3.5\%) and 7 with XLI (2.5\%). Palmoplantar keratoderma (PPK) was seen in 42 (15\%) patients of the 284, 25 (9\%) patients with CIE, and $17(6 \%)$ patients with LI. Nail abnormalities were observed in 22 cases of the 284 (4.6), 13 with CIE (4.6), and
9 with LI (3.2). Atopic dermatitis was reported in 38 patients out of 284, all of them had IV.

\section{Ocular findings}

Ectropion was observed in 12/108 (11\%) of patients with LI, and $24 / 76$ (31.6\%) of patients with CIE. Corneal opacity was observed in 16/30 (53\%) patients with XLI. Recurrent conjunctivitis mostly of the bacterial type was

Table 1. Epidemiological features and clinical findings in 284 patients with hereditary ichthyosis

\begin{tabular}{|c|c|c|c|c|c|c|}
\hline Clinico-epidemiologic data & $\begin{array}{l}\text { Ichthyosis } \\
\text { vulgaris (IV) } \\
(\%)\end{array}$ & $\begin{array}{l}\text { X-linked ichthyosis } \\
\text { (XLI) (\%) }\end{array}$ & $\begin{array}{l}\text { Lamellar } \\
\text { ichthyosis } \\
\text { (LI) (\%) }\end{array}$ & $\begin{array}{l}\text { Congenital } \\
\text { ichthyosiform } \\
\text { erythroderma } \\
\text { (CIE) (\%) }\end{array}$ & $\begin{array}{l}\text { Sjogren-Larsson } \\
\text { syndrome } \\
\text { (SLS) (\%) }\end{array}$ & Total (\%) \\
\hline Patients, number (\%) & $38(13.4)$ & $30(10.6)$ & $108(38)$ & $76(26.8)$ & $32(11.3)$ & $284(100)$ \\
\hline Egyptian nationality & 13.4 & 10.56 & 38 & 26.76 & 11.26 & 100 \\
\hline Sex: male & 5.63 & 9.85 & 15.49 & 11.26 & 6.33 & 48.59 \\
\hline Positive parental relationship & 9.15 & 7.39 & 32.39 & 21.83 & 8.09 & 78.87 \\
\hline Positive family history & 10.17 & 7.36 & 31.22 & 18.94 & 3.85 & 71.57 \\
\hline \multicolumn{7}{|l|}{ Age of onset: } \\
\hline Onset at birth/neonatal period & - & 7.4 & 38 & 26.8 & 2.9 & 75 \\
\hline $\begin{array}{l}\text { Onset after } 1 \text { month of life } \\
(1-3 \mathrm{~m})\end{array}$ & 13.4 & 3.2 & - & - & 8.5 & 25 \\
\hline \multicolumn{7}{|l|}{ Skin lesions: } \\
\hline $\begin{array}{l}\text { Collodion baby or exaggerated } \\
\text { skin desquamation and peeling } \\
\text { at birth }\end{array}$ & - & 4.2 & 38 & 26.76 & & 69 \\
\hline Diffuse erythema and scaling & & & & & 11.3 & 11.3 \\
\hline $\begin{array}{l}\text { Generalized scales, which range } \\
\text { from fine and white to thick, } \\
\text { dark and plate like }\end{array}$ & - & - & $\begin{array}{l}15 \text { Coarse } \\
\text { plate-like } \\
\text { scales }\end{array}$ & $\begin{array}{l}16 \text { Fine grey white } \\
\text { scales }\end{array}$ & & 31 \\
\hline $\begin{array}{l}\text { Adherent brown scales/extensor } \\
\text { surfaces }\end{array}$ & 13.4 & 10.6 & - & - & - & 24 \\
\hline Preserved flexures & 13.38 & 10.56 & - & - & - & 24 \\
\hline Dandruff & 5.3 & 2.5 & 3.5 & 14 & & 25.3 \\
\hline Palmoplantar keratoderma & & & 6 & 9 & & 15 \\
\hline Nail abnormalities & & & 3.2 & 4.6 & & 7.7 \\
\hline Atopic dermatitis & 13.4 & & & & & 13.4 \\
\hline Corneal opacity & & 5.6 & & & & 5.6 \\
\hline Ectropion & - & - & 4.2 & 8.4 & - & 12.7 \\
\hline Recurrent conjunctivitis & & 2.5 & 4.2 & 3.2 & & 9.9 \\
\hline $\begin{array}{l}\text { Mental retardation/learning } \\
\text { difficulties }\end{array}$ & - & 2.8 & - & 3.2 & 11.3 & 17.3 \\
\hline Seizures/muscle spasms & - & - & - & - & 11.3 & 11.3 \\
\hline Speech defect & - & - & & & 6 & 6 \\
\hline Growth retardation/short stature & - & - & 15 & 5 & 2 & 21.4 \\
\hline Eclabion & & & 19.4 & 6 & & 25.4 \\
\hline Alopecia & - & - & 3.5 & 6 & - & 9.5 \\
\hline
\end{tabular}


observed in 9/76 (12\%) patients with CIE, 12/108 (11\%) patients with $\mathrm{LI}$ and $7 / 30$ (23\%) of patients with XLI.

\section{Other medical associations}

Forty-nine (17.3\%) of our PHI patients were reported to have mental retardation (MR) or learning difficulties compared with their unaffected siblings or peers. All SLS patients had mental retardation or learning difficulties. Eight XLI patients (8/30; 27\%), and 9 CIE cases (9/76; $12 \%)$ had also learning difficulties. Seizures or muscle spasms were reported in all patients with SLS. Speech defect was reported in 17 patients with SLS (17/284; 6\%). Of the 284 patients, 61 (21.4\%) were below the third percentile for weight or height; 42 (15\%) had LI, 14 had CIE (5\%), and 5 patients with SLS (2\%). Alopecia areata (AA) was reported in $17 / 76$ patients with NBCIE (22.4\%) and 10/108 patients with LI (9.3\%). Eclabion (eversion of the lips) was seen in 72 cases; 55 with $\mathrm{LI}$ and 17 with CIE.

Table 2. Associated medical conditions defined among relatives of 284 patients with $\mathrm{PHI}$

\begin{tabular}{|c|c|c|}
\hline $\begin{array}{l}\text { Associated medical conditions among } \\
\text { relatives }\end{array}$ & Number & $\%$ \\
\hline Polydactyly & 6 & 6.316 \\
\hline IDDM & 3 & 3.158 \\
\hline Glaucoma & 1 & 1.053 \\
\hline Osteogenesis imperfecta & 1 & 1.053 \\
\hline Isolated growth hormone deficiency & 1 & 1.053 \\
\hline Goitre & 1 & 1.053 \\
\hline Congenital heart diseases & 4 & 4.211 \\
\hline GMME & 14 & 14.737 \\
\hline Hypertension & 11 & 11.579 \\
\hline Bronchial asthma & 3 & 3.158 \\
\hline Anencephaly & 1 & 1.053 \\
\hline Squint & 1 & 1.053 \\
\hline Allergic dermatitis & 4 & 4.211 \\
\hline Psoriasis & 3 & 3.158 \\
\hline Vitiligo & 2 & 2.105 \\
\hline Tumors & 6 & 6.316 \\
\hline Peptic ulcer & 1 & 1.053 \\
\hline Mental deficiency & 12 & 12.632 \\
\hline Infertility & 7 & 7.368 \\
\hline Talipus equinovarus & 4 & 4.211 \\
\hline Deaf mutism & 4 & 4.211 \\
\hline Speech defect & 2 & 2.105 \\
\hline Short stature & 2 & 2.105 \\
\hline Hydrocephalus & 1 & 1.053 \\
\hline Total & 95 & 100.000 \\
\hline
\end{tabular}

\section{Associated medical conditions among relatives}

Ninety-five associated medical conditions were defined among relatives of 284 patients with ichthyosis (33.5\%) (Table 2).

\section{Discussion}

Although ichthyoses are rare disorders, they require costly long-term medical management, and thus there is a need for efficient preventive and therapeutic strategies [9]. Prevalence rates among Middle Eastern populations are unknown; however, the high frequency of consanguineous marriages characteristic of these populations suggests that due to their mode of inheritance, these diseases may be particularly common in this region [8, 10]. There is limited clinico-epidemiological information on PHI outside of North America and Europe [11, 12]. To our best knowledge, there are no recent published reports in the medical literature about the incidence of $\mathrm{PHI}$ in Egypt. We present a preliminary survey of $\mathrm{PHI}$ in the population of the Eastern Province of Egypt.

Our study shows that the occurrence rate of $\mathrm{PHI}$ was $25.7 \%$ of genodermatosis patients attending the genetics clinics and 1 per 2359 patients attending the Pediatric Hospital, Ain Shams University, Cairo, Egypt. The occurrence rate of $\mathrm{PHI}$ in the Eastern Province of Saudi Arabia study was $0.67 \%$ or 7 per 1000 new dermatology cases [6]. In addition, another study stated that the incidence of moderate to severe ichthyosis is 5 to 10 per 100,000 people every year in the United States [12]. The high occurrence rate in our study probably reflects a high incidence of $\mathrm{PHI}$ in Egyptian population, which is possibly secondary to high consanguinity rates in the parents of Egyptian patients. Male to female ratio in our study was $0.9: 1$. This was different from other studies, in which a male predominance was found $[6,13]$.

Consanguineous marriage was reported among 79\% of the parents of our patients, which was significantly high being most noticeable in LI parents (32\%). Our results were similar to those of Shawky et al., who stated that the rate of consanguineous marriage is high in Egypt (35.3\%), especially among first cousins (86\%) [14]. Consanguineous marriage was also reported among $64 \%$ of Egyptian ichthyosis patients in another study [13]. The high frequency in these two studies was attributed to the traditional intrafamilial cousin first degree marriage in Egyptian families. On the other hand, a study in 2008 reported that parental consanguinity was noted in $60 \%$ of Tunisian patients [15]. Our study showed a high proportion of patients with a positive family history (72\%). Similar results were reported by another study (75\%) [6], while it was $25.7 \%$ in a Tunisian study [15].

The commonest type of ichthyosis in our study was LI (38\%) followed by CIE which constituted $26.8 \%$ of all cases. This was in agreement with Shawky et al. [13] who performed a study on genodermatoses prevalent among 
Egyptian children. The most common type was ichthyosis (26.5\%), of whom LI was the most common (88\%) followed by IV (12\%). Inherited as an autosomal recessive trait, the high rate of $\mathrm{LI}$ and CIE in the Eastern Province of Egypt possibly reflects high rates of consanguinity in this region. On the other hand, the incidence of LI was $5.6 \%$ in a study done in Saudi Arabia, 2006 [7]. This was in contrast to the results of other studies that considered $\mathrm{CIE}$ a rare or uncommon inherited ichthyosiform dermatosis [16-19].

In our study, the frequency of IV was 38/284 (13.4\%) and XLI was 30/284 (10.6\%). SLS was detected in $11.3 \%$ of our patients. This was in contrast to another study which reported that the commonest type of ichthyosis was IV (44.7\%), followed by CIE (29.6\%), XLI (16.9\%), LI (5.6\%) and EH (4.2\%) [7]. In addition, a study in 2006 reported that IV is the most common inherited disorder of keratinization [20]. These different incidences that are characteristic for each geographic region, may be reflected in the genotypes of specific ethnic groups [11, 16].

Dandruff was found in $25 \%$ of our patients and PPK in $15 \%$. Our findings are consistent with observations in the literature $[4,6,20]$. Atopic dermatitis mostly accompanied by asthma and pruritus, was reported in $13.4 \%$ of our patients, all of them had IV which is considered the most common type of $\mathrm{PHI}$ reported to be associated with atopic dermatitis in the medical literature [20, 21].

Forty-nine (17.3\%) patients of our PHI group were reported to have mental retardation (MR) or learning difficulties compared with their unaffected siblings or peers. All SLS patients had mental retardation or learning difficulties. Eight XLI patients (8/30;27\%), and 9 CIE cases (9/76; 12\%) had also learning difficulties. A study in 2005 reported that mental retardation can be seen in some $\mathrm{XLI}$ patients and is thought to be due to deletions encompassing neighboring genes [22]. Speech defects were reported in 17 patients with SLS (17/32; 6\%). Speech defects are a common finding in SLS cases [23]. Twenty-one percent of our patients were below the third percentile for weight or height. These findings were also reported previously [20]. Alopecia was reported in 17/76 patients with CIE (22.4\%) and 10/108 patients with LI (9.3\%). This finding was consistent with previous reports [4, 20]. Eclabion was seen in 55 cases with $\mathrm{LI}$ and 17 cases with CIE. Eclabion is a characteristic clinical feature of $\mathrm{LI}[4,6]$.

Ninety-five associated medical conditions were defined among relatives of 284 (33.5\%) patients with ichthyosis. Genealogic analysis of pedigrees of index patients with ichthyosis revealed an apparently high incidence of other genetic anomalies which manifested simultaneously or segregated randomly among many of proband's relatives. The identification of isolated ichthyosis as well as isolated deafness or mental deficiency among certain index kindreds, could advocate the possibility of linkage of mutant gene loci mediating both types of anomalies.
Due to the recent advances in our understanding of the genetic defects underlying severe congenital ichthyosis, it has become possible to make DNA-based prenatal diagnoses for congenital ichthyosis families by sampling chorionic villus or amniotic fluid in the earlier stages of pregnancy. That lowers the risk to fetal health and reduces the burden on mothers compared with prenatal diagnoses by fetal skin biopsy [24]. Molecular diagnosis is a crucial diagnostic tool and has become in some countries the gold standard for the diagnosis of the ichthyoses and Mendelian disorders of cornification (MEDOC) in general [4]. Several powerful tools for the treatment of genetic disorders, such as siRNA gene silencing technology, read-through compounds to read through nonsense mutations, and improved corrective gene transfer techniques have been introduced. Fortunately, the skin is the most easily accessible organ for these novel treatment approaches. Thus, the development of novel, highly effective therapeutic methods in the near future is expected [24].

\section{Conclusions}

This study shows that the occurrence rate of PHI was $25.67 \%$ of genodermatosis patients attending the Pediatric Clinic, Ain Shams University, Cairo, Egypt between January 2000 and December 2013. The male to female ratio was of $0.9: 1$. Consanguinity among the parents was significantly high being most noticeable in LI parents. The commonest type of ichthyosis in our study was LI followed by CIE. Sixty-nine percent of our patients were born with collodion membranes. Our survey reflects the geographic and ethnic variation in the incidence and clinical features of this group of genodermatoses and highlights the importance of prenatal diagnosis in this region.

\section{Acknowledgments}

The authors would like to thank for the cooperation of the new patients who accepted to be enrolled in the study and the cooperation of the whole genetics unit.

This study was conducted at the Pediatric Hospital, Ain Shams University, Cairo Egypt.

\section{Conflict of interest}

The authors declare no conflict of interest.

\section{References}

1. Schmuth M, Martinz V, Janecke AR, et al. Inherited ichthyoses/generalized Mendelian disorders of cornification. Eur J Hum Genet 2013; 21: 123-33.

2. Schmuth M, Gruber R, Elias PM, Williams ML. Ichthyosis update: towards a function-driven model of pathogenesis of the disorders of cornification and the role of corneocyte proteins in these disorders. Adv Dermatol 2007; 23: 231-56. 
3. Elias PM, Williams ML, Holleran WM, et al. Pathogenesis of permeability barrier abnormalities in the ichthyoses: inherited disorders of lipid metabolism. J Lipid Res 2008; 49: 697-714.

4. Oji V, Tadini G, Akiyama M, et al. Revised nomenclature and classification of inherited ichthyoses: results of the First Ichthyosis Consensus Conference in Sorèze 2009. J Am AcadDermatol 2010; 63: 607-41.

5. Liu JJ, Yuan YY, Zhang XQ, et al. Mutations of transglutaminase- 1 in Chinese patients with autosomal recessive congenital ichthyosis: a case report with clinical and genetic analysis of Chinese cases reported in literature. Clin Exp Dermatol 2015; 40: 56-62.

6. Al-Zayir AA, Al-AmroAlakloby OM. Primary hereditary ichthyoses in the Eastern Province of Saudi Arabia. Int I Dermatol 2006; 43: 415-9.

7. Russell LR, DiGiovanna JJ, Hashem N, et al. Linkage of autosomal recessive lamellar ichthyosis to chromosome 14q. Am J Hum Genet 1994; 56: 1146-52.

8. Shawky RM, Sayed NS, Elhawary NA. Mutations in transglutaminase 1 gene in autosomal recessive congenital ichthyosis in Egyptian families. Dis Markers 2004; 20: 325-32.

9. Styperek AR, Rice ZP, Kamalpour L, et al. Annual direct and indirect health costs of the congenital ichthyoses. Pediatr Dermatol 2010; 27: 325-36.

10. Alwan A, Modell B. Recommendations for introducing genetics services in developing countries. Nat Rev Genet 2003; 4: 61-8.

11. Cuevas-Covarrubias SA, Díaz-Zagoya JC, Rivera-Vega MR, et al. Higher prevalence of $X$-linked ichthyosis vs. ichthyosis vulgaris in Mexico. Int J Dermatol 1999; 38: 555-60.

12. Milstone LM, Miller K, Haberman M, Dickens J. Incidence of moderate to severe ichthyosis in the United States. Arch Dermatol 2012; 148: 1080-1.

13. Shawky RM, El Kahky H, Mohamed HA, El Baz F. Genodermatoses prevalent among Egyptian children. J Pan-Arab League Dermatologists 1998; 9: 79-85.

14. Shawky RM, El-Awady MY, Elsayed SM, Hamadan GE. Consanguineous matings among Egyptian population. Egypt J Med Hum Genet 2011; 12: 157-63.

15. Kharfi M, El Fekih N, Ammar D, et al. Hereditary ichthyosis in Tunisia: epidemiological study of 60 cases. Tunis Med 2008; 86: 983-6.

16. Baruah MC, Oeducoumar P, Garg BR, Kumar V. Clinico-epidemiological profile of ichthyosis in south Indian patients. J Dermatol 1995; 22: 486-91.

17. Rossmann-Ringdahl I, Anton-Lamprecht I, Swanbech G. A mother two children with nonbullous congenital ichthyosiform erythroderma. Arch Dermatol 1986; 122: 559-64.

18. Ebling FJG, Marks R, Rook A. Ichthyosis. In: Textbook of Dermatology. $4^{\text {th }}$ ed. Vol. 2. Oxford University Press, Bombay 1987; 1416-35.

19. Smith FJ, Irvine AD, Terron-Kwiatkowski A, et al. Loss-offunction mutations in the gene encoding filaggrin cause ichthyosis vulgaris. Nat Genet 2006; 38: 337-42.

20. Patterson JW. Disorders of epidermal maturation and keratinization and connective tissues. In: Practical Skin Pathology: A Diagnostic Approach. $1^{\text {st }}$ ed. Saunders, Philadelphia 2013; 231-49.

21. Rabinowitz LG, Esterly NB. Atopic dermatitis and ichthyosis vulgaris. Pediatr Rev 1994; 15: 220-6.

22. Van Esch H, Hollanders K, Badisco L, et al. Deletion of VCX-A due to NAHR plays a major role in the occurrence of mental retardation in patients with X-linked ichthyosis. Hum Mol Genet 2005; 14: 1795-803.

23. Dutra LA, de Aquino CC, Barsottini OG. Sjogren-Larsson syndrome: case report and review of neurologic abnormalities and ichthyosis. Neurologist 2009; 15: 332-4.

24. Akiyama M. Updated molecular genetics and pathogenesis of icthyosis. Nagoya J Med Sci 2011; 73: 79-90. 